\title{
Intragenomic homogeneity on Liberibacter 16S rDNA confirms phylogeny and explains ecological strategy
}

\author{
Warrick R. Nelson ${ }^{1 *}$, Nelson A. Wulff ${ }^{2}$, Joseph M. Bové ${ }^{3}$ \\ ${ }^{1}$ The New Zealand Institute for Plant \& Food Research Limited, Private Bag 4704, Christchurch 8140, New Zealand \\ ${ }^{2}$ Departamento de Pesquisa \& Desenvolvimento, Fundecitrus, Araraquara, SP, 14807-040, Brazil \\ ${ }^{3}$ UMR-1332 Biologie du Fruit et Pathologie, INRA, Université Bordeaux Ségalen, Villenave d'Ornon, France \\ *Corresponding author: warrick.nelson@ plantandfood.co.nz
}

\section{Abstract}

Three of the five currently recognized "Candidatus Liberibacter" spp., "Ca. L. asiaticus" (Las), "Ca. L. americanus" (Lam) and "Ca. L. solanacearum", and the newly erected genus Liberibacter species, L. crescens (Lcr), have had their genomes sequenced. In all four cases there are three homogeneous copies of the 16S rRNA gene, one present as the reverse complement of the other two. 16S intragenic homogeneity is common within the $\alpha$-Proteobacteria. The presence of three 16S rRNA copies indicates an advantage for a rapid response of population increase to favourable growth conditions. The metabolic cost of carrying multiple copies is avoided during periods of low cellular activity as this situation occurs at low temperatures, for example overwintering in deciduous plants or in a dormant insect host.

A large insertion in the $16 \mathrm{~S}$ rDNA sequence of three species compared to the other three species indicates a dichotomy in the Liberibacter genus and provides a phylogenetic signal of closeness to the proximal node within the Rhizobiaceae. In spite of similar symptoms in Citrus crops associated with Lam and Las infections, these species belong on either side of this dichotomy, thus confirming Lam as phylogenetically closer to the proximal node than Las.

\section{Introduction}

The bacterial 16S rRNA gene is highly conserved and thus serves as a very useful marker of evolutionary relatedness in phylogenetic studies [1]. Bacterial species may contain one or more copies of this gene. A single copy is common where bacteria need to conserve resources as there is a metabolic cost associated with multiple copies, for example in an environment poor in nutrients and thus limiting growth potential [2]. Multiple homogeneous copies occur in species adapted to environments where speed of multiplication is important because of only temporarily good growth conditions [3]. Concerted evolution generally maintains these as homogeneous copies, probably because of a metabolic cost associated with combined expression of heterogeneous copies [4]. Multiple but heterogeneous copies have been recorded where the $16 \mathrm{~S}$ gene copies are so different as to be able to function under very different conditions, especially particularly high or low temperatures, thus adapting the bacteria to grow across a broader temperature range than normal [5]. However, because the $16 \mathrm{~S}$ gene is so commonly used as a phylogenetic marker, intragenic heterogeneity has resulted in an overestimation of bacterial species diversity $[6,7]$.

Liberibacter species are new to science, commonly in association with significant crop damage, especially of citrus, potato, tomato, carrot, celery and their close relatives [8]. They are members of the Rhizobiaceae family in the $\alpha$ division of Proteobacteria [9] and are described as obligate intracellular endogenous bacteria with an alternating insect (psyllid)/plant host life cycle. The insect/plant host species composition varying primarily by liberibacter species [8]. The earliest speciation event by molecular clock technique is 309 Ma [10], supported by biogeography to a putative Pangaean origin [11]. Six species have so far been discovered and named.

The genus "Candidatus Liberibacter" and the two species "Ca. L. africanus" (Laf) and "Ca. L. asiaticus" (Las), associated with huanglongbing (HLB) disease in citrus crops, were first described by Jagoueix, Bové and Garnier [9]. While the genome of Laf has not yet been sequenced, the Las genome sequence has been obtained from five different sources [12-16]. Comparison of a large number of Las 16S rDNA sequences indicates that there is a single haplotype in this species $[17,18]$ in spite of the very wide geographic spread it has now reached [19]. Las has been reported to exist in a number of genetic groupings, depending on the DNA segment analysed [20] and the divergence on other DNA segments may be more useful for epidemiological purposes. Las is also known from close citrus relatives commonly grown for ornamental and culinary purposes, especially Murraya species [21-23].

"Ca. L. americanus" (Lam) is also associated with HLB in citrus crops [24], as well as infecting Murraya paniculata [25]. The Lam genome has been sequenced [26]. At present this species has only been reported from Brazil; single reports from China and Texas (USA) have not been confirmed.

"Ca. L. solanacearum" (Lso) [27] (syn "Ca. L. psyllaurous") [28] is associated with diseases of Solanaceae crops (especially potato and tomato) in North America and Apiaceae crops (especially carrot and celery) in Europe [29] and North Africa [30]. Five haplotypes with geographic and psyllid/plant host differences have been described, designated LsoA, B, C, D and E [31-33]. The genome has been sequenced [34], most likely the B haplotype.

Liberibacter crescens (Lcr), as the only cultured species within the liberibacters, is the first representative of the new genus Liberibacter to be validly published and named [35]. This species has been isolated from expressed sap of a defoliating mountain papaya in Puerto Rico [35]. The insect phase is currently unknown. The $L$. crescens genome has been sequenced [36].

Taxonomic errors may occur in the presence of intragenomic heterogeneity on the 16S rRNA gene [7] and it is known that liberibacter genomes may hold more than one $16 \mathrm{~S}$ gene copy [37]. By combining knowledge of the $16 \mathrm{~S}$ gene copy number and heterogeneity, phylogenetic status and some clear pointers to the evolutionary responses to the intracellular conditions can be deduced for the liberibacter species.

\section{Materials and Methods}

Liberibacter genomes were identified in the GenBank database (http://www.ncbi.nlm.nih.gov/genome/?term= liberibacter), and the 16S rDNA sequences downloaded after identifying the genes through the sequence annotations. These annotations also indicate position of the gene within the genome, orientation and length, summarised in Table 1. Sequences were aligned in ClustalX v2.1 [38]. 
bioRxiv preprint doi: https://doi.org/10.1101/016188; this version posted March 8, 2015. The copyright holder for this preprint (which was not certified by peer review) is the author/funder, who has granted bioRxiv a license to display the preprint in perpetuity. It is made available under aCC-BY-ND 4.0 International license.

Minimal free energy and the thermal stability curves were calculated using RNAdraw v1.1b2 [39] with the specific sequences used indicated in Table 1. Escherichia coli (E.coli GenBank BA000007) and Campylobacter jejuni (Campy GenBank AL111168.1) were added for comparison as they are also Proteobacteria but in the $\gamma$ and $\varepsilon$ divisions respectively.

Table 1. 16S rDNA operons and nucleotide numbers within the genome. * indicates operon used for thermal stability curves calculated with RNAdraw in Figure 2. (C) indicates complement orientation.

\begin{tabular}{|c|c|c|c|c|}
\hline Species & GenBank & Length & Gene position & Source \\
\hline \multirow[t]{3}{*}{ Lam } & СР006604.1 & 1488 & (C) $150786 . .152273$ & [26] \\
\hline & & 1488 & $585655 . .587142^{*}$ & \\
\hline & & 1488 & (C)993592..995079 & \\
\hline \multirow[t]{3}{*}{ Las } & CP001677.5 & 1511 & (C)416812..418322 & [12] \\
\hline & & 1507 & $786255 . .787761^{*}$ & \\
\hline & & 1507 & $854295 . .855801$ & \\
\hline \multirow[t]{3}{*}{ Las } & CP004005.1 & 1507 & (C) $401877 . .403383$ & [41] \\
\hline & & 1507 & 770853..772359 & \\
\hline & & 1505 & $838837 . .840341$ & \\
\hline \multirow[t]{3}{*}{ Las } & AP014595.1 & 1511 & (C) $409084 . .410594$ & [13] \\
\hline & & 1497 & $778382 . .779878$ & \\
\hline & & 1507 & $846384 . .847890$ & \\
\hline \multirow[t]{3}{*}{ Lso } & CP002371.1 & 1509 & $305984 . .307492^{*}$ & [34] \\
\hline & & 1507 & $614323 . .615829$ & \\
\hline & & 1507 & (C) $1004828 . .1006334$ & \\
\hline \multirow[t]{3}{*}{ Lcr } & CP003789.1 & 1507 & $326080 . .327586^{*}$ & {$[36]$} \\
\hline & & 1506 & (C) $1069942 . .1071447$ & \\
\hline & & 1507 & (C) $1466094 . .1467600$ & \\
\hline E.coli & BA000007 & 1542 & $227102 . .228643^{*}$ & \\
\hline Campy & AL111168.1 & 1513 & $39249 . .40761^{*}$ & \\
\hline
\end{tabular}

\section{Results}

The genomes of all four species of liberibacter, Las, Lso, Lam and Lcr, contain three copies of the 16S rRNA gene with one copy as the reverse complement of the other two. Aligning all three copies per genome retained the clear species separation as previously reported [11], with almost complete intragenomic homogeneity. The main differences were at the ends, most likely representing difficulty in determining the up- and down-stream promoter regions. A few single nucleotide polymorphisms (SNPs), indicating minor heterogeneity between copies, are more likely to be sequencing errors as a comparison at species level against many other accessions from GenBank do not repeat these SNPs (data not shown).

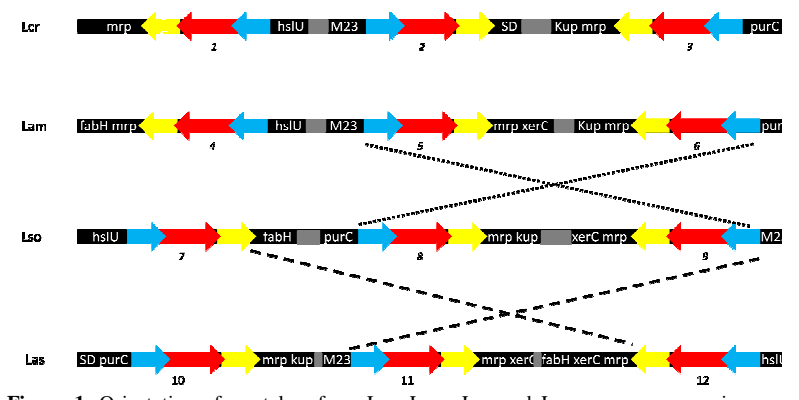

Figure 1. Orientation of rrn taken from Lcr, Lam, Lso and Las genomes, assuming rrn starting from dnaA gene, as observed in Lam [26]. Dotted lines between Lam/Lcr and Lso

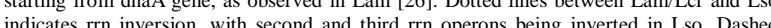
indicates nn inverine lines between Lso and Las incoles in inversion, wh the fiss in being inverted and located as the third 23SrDNA and yellow an a succinocarboxamide synthase), mrp (multiple resistance and $\mathrm{pH}$ adaptation), xerC gen (site-specific tyrosine recombinase), fabH gene (3-oxoacyl-[acyl-carrier-protein] synthase III), kup (potassium uptake transporter), hsIU (ATP-binding subunit from the ATPdependent protease); M23 (peptidase M23), SD (superoxide dismutase). Numbers in italics indicate rrn operon. Not to scale.

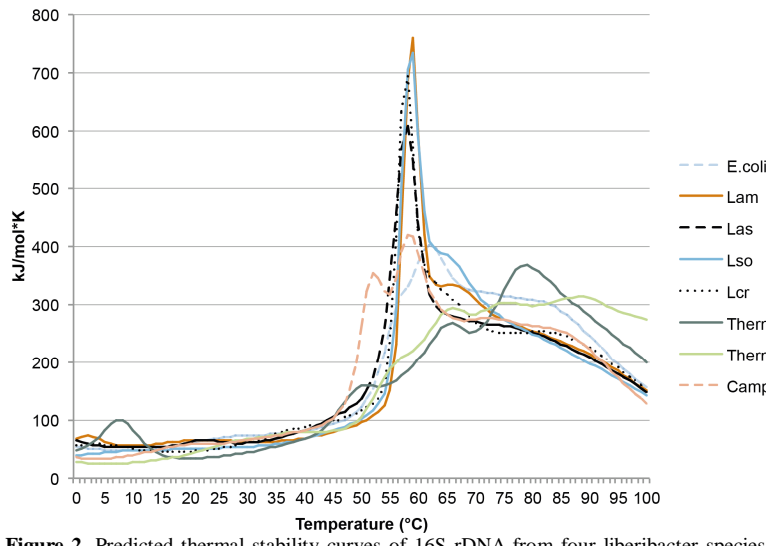

Figure 2. Predicted thermal stability curves of $16 \mathrm{~S}$ rDNA from four liberibacter species plus E.coli and Campy for comparison, the specific copy illustrated is indicated in Table 1, as well as Thermoanaerobacter tengkongensis (GenBank AE008691) 16S operons ThermoA and ThermoC [5] illustrating possible differences of rRNA genes within
bacterial species.

Although several rearrangements have taken place in liberibacter genomes [26, 36, 42], a high degree of gene conservancy is observed in the vicinity of ribosomal operons in all liberibacter genomes sequenced to date. If we order all genomes starting from the $d n a \mathrm{~A}$ gene, this conservancy is clearly shown in Figure 1. For instance, the three ribosomal operons of Lcr have the same orientation as those of the phylogenetically close Lam [35]; similarly, for Lso and Las, the orientation is also the same [11], but different from the Lcr/Lam orientation. In addition, mrp is located immediately downstream of the 5SrRNA gene 10 times out of 12 , irrespectively of ribosomal operon orientation (compare operon 5 and 9, 6 and 8, as well as 7 and 12,9 and 11).

Thermal stability curves show similarities across the liberibacter species with marked differences to E.coli and Campy (Figure 2). Even more marked are the differences at higher temperature ranges for DNA derived from thermotolerant extremophiles. However, possibly more interesting is the almost complete lack of differences in the $10-40^{\circ} \mathrm{C}$ range (Figure 2 ).

Comparing the 16S rRNA genes of the Lso genome sequenced (Table 1, Lso CP002371.1) with other Lso 16S accessions, indicates that the sequenced genome corresponds to haplotype LsoB, although it is not specifically identified as such. This haplotype has been associated with symptomatic

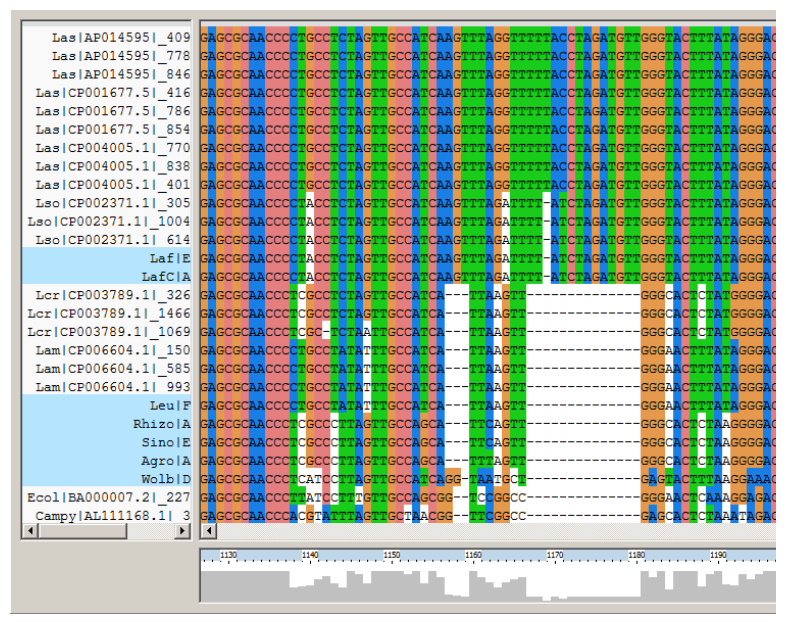

Figure 3. Partial screen capture of the ClustalX alignment showing the 14/13bp length insertion in the Las/Lso sequences compared to Lam/Lcr and E.coli/Campy, Other $\alpha$ proteobacteria species are highlighted including two other liberibacter species, " $\mathrm{Ca}$. L. africanus" (Laf, GenBank EU921619) and subspecies capensis (LafC, GenBank AF137368), "Ca. L europaeus" (Leu, GenBank FN678792), the more distantly related AFizize "Ca. L europaeus" (Leu, GenBank FN678792), the more distantly related Rhizobiaceae species Rhizobium leguminosarum (Rhizo, GenBank AY509900), Sinorhizobium chiapanecum (Sino, GenBank EU286550), Agrobacterium tumefaciens (Agro, GenBank AJ389907) and another $\alpha$-proteo 
solanaceous crops of Central USA, East of the Rocky Mountains [31]. One of the copies from the sequenced genome has two SNPs, indicating LsoA haplotype. This could suggest that the source of liberibacter for genome assembly was a mixed haplotype infection, reinforced by the SNPs noted earlier in this species on the 23S and 5S genes. Mixed infections with these two haplotypes have been reported [43].

Although the Lcr gene is reported as longer than the Lam version, closer inspection of the sequences indicates no other insertions, but rather variation in reporting at both the 5' and 3' ends accounts for the discrepancy.

A large insertion of up to 14 nt occurs in Las and Lso (Figure 3). This insertion is positioned at nucleotides 1141/1142 of E.coli 16S rRNA gene. In E.coli this nucleotide locates inside helix 39 [44], which interacts with proteins S10 and S9, also present in liberibacter genomes. That this is an insertion event in Las and Lso is illustrated by the lack of these nucleotides in related Rhizobiaceae species as well as the more distantly related Proteobacteria species.

\section{Discussion}

Intragenomic homogeneity of multiple $16 \mathrm{~S}$ operons within $\alpha$-proteobacteria is common [45] and liberibacter species fit this pattern. Concerted evolution is a driver towards homogeneity as heterogeneity comes at a metabolic cost [4]. The metabolic cost of heterogeneity is of lesser evolutionary importance only where other drivers occur, such as adaptation to extremes of temperature as illustrated in some extremophiles, for instance Thermoanaerobacter species [5].

Most bacteria possess one or two copies of the 16S gene, with three or more copies being considerably less common [7]. Proteobacteria generally have an average copy number of 3.94 , but removing the much higher number common in the $\gamma$ division results in fewer than 3 copies for the rest of the proteobacteria [45]. Thus the three copies in the liberibacters is towards the high side for a species in the $\alpha$ division.

Some studies suggest that liberibacters face competition within their plant phloem environment [46, 47] and their insect host microbial biome [48]. Retention of a relatively high number of $16 \mathrm{~S}$ copies suggests an evolutionary advantage of a rapid increase in population in response to an improved environment for reproduction. However, a more detailed microbial diversity analysis specifically of phloem cells suggests a very limited microbial competition for liberibacter [49]. The many studies using electron microscopy easily identify liberibacter bacteria in symptomatic tissues of infected plants and no or fewer liberibacters in the phloem of infected, but yet asymptomatic plants; bacteria other than liberibacters are not detected in the phloem of infected plants. The evolutionary advantage for liberibacter species of multiple $16 \mathrm{~S}$ copies therefore does not derive from competition with other bacterial species. Possibly the advantage derives from relatively short periods of high nutrient availability during the main growing season of both plant and insect phases. This would suggest strong seasonal differences in growth rates of these hosts.

However, the metabolic cost of the copy number may play a role as evidenced by apparently low titre in plant hosts during periods of low growth but higher titre during growth flushes of citrus $[50,51]$ or after storage in seed tubers of potatoes $[52,53]$. An extreme of survival in root systems, even after the tree has been killed [54], indicates the potential for long term survival even in a dormant host. Deciduous plants exhibit winter dormancy and presumably the metabolic cost to liberibacter of multiple rRNA genes is less important at low temperatures common in these conditions. This suggests an evolutionary advantage of a higher copy number to increase population size rapidly when growth conditions are favourable while the metabolic costs are reduced because of low growth conditions for liberibacter in the dormant plant and/or insect phases.

Liberibacter species are known to be relatively intolerant of high temperatures, with Las being regarded as the most tolerant. Las can be eliminated from plants exposed to $42^{\circ} \mathrm{C}$ [55] while Lam and Lso were not transmitted to host plants at temperatures above $32^{\circ} \mathrm{C}[56,57]$. Thermal stability curves for 16S (Figure 2), while suggesting minor differences between species, do not indicate the major differences in thermal stability of intragenomically divergent $16 \mathrm{~S}$ copies in thermophilic extremophiles such as in Thermoanaerobacter [5]. For example, the thermal stability curves for Campy and E.coli also do not indicate that the $16 \mathrm{~S}$ gene is involved in determining growth temperatures, Campy has a growth range of $30-46^{\circ} \mathrm{C}$ [58] and E.coli an optimum of $37^{\circ} \mathrm{C}$ [59]. There is a danger of anticipating that intergenomic heterogeneity of $16 \mathrm{~S}$ copies is associated with sensitivity to different temperatures. These observations suggest that this might only be the case for some extreme thermophilic bacteria and differences in optimal and survival temperature responses in liberibacter species are not as a result of $16 \mathrm{~S}$ gene sensitivity.

Heat sensitivity suggests a cooler climate requirement, yet some of the regions where liberibacters are a problem in crops are not cool during the summer months. If foliage in these hotter periods becomes too hot for liberibacter survival, presumably the bacteria survive within the plants in cooler plant parts, especially in below ground parts, such as roots and tubers. This could explain the observation that plant sampling for liberibacter detection appears to be more reliable from roots or low down on the plant $[51,60]$.

Assuming that the small number of SNPs between copies in the same genome represent sequencing ambiguities or errors rather than true intragenomic heterogeneity, there has clearly been sufficient time for concerted evolution to be effective after species and haplotype separation. Although it is commonly stated that genomic variation is accelerated in obligate endosymbionts, this is unlikely to be true of what is effectively a clonal system on the highly conserved $16 \mathrm{~S}$ gene and within the highly ecologically constrained biome of these obligate intracellular endogenous bacteria, as opposed to genomic loss of genes coding for proteins available from the host environment. Thus we can have simultaneously large and rapid changes at the genome level combined with almost no variation on highly conserved genes such as $16 \mathrm{~S}$, hence the value of the $16 \mathrm{~S}$ gene for taxonomic purposes [1]. No changes in 16S rRNA genes and also no major changes in upstream associated ORFs (Figure 1) support genomic variation largely by gene loss rather than gene rearrangements.

The large insertion event representing about $0.9 \%$ of the gene (Figure 3) occurs within Las and Lso genomes but not in Lam or Lcr. Adding $16 \mathrm{~S}$ sequences for the other liberibacter species but without genome sequences available (Laf, Leu) as well as a number of other Rhizobiaceae and more distantly related proteobacterial species, demonstrates this is an insertion event in the precursor species prior to Las and Lso speciation. This observation confirms that Lam is more closely positioned phylogenetically to the proximal node of the Rhizobiaceae than Las or Lso [40]. Clearly, the species form two phylogenetic clusters, those evolving prior to this insertion (Lam, Lcr, Leu) and those evolving from a common ancestor after this large insertion event (Laf, Las, Lso). This phylogenetic clustering is also supported by the gene arrangements and inversions illustrated in Figure 1, thus a dichotomy occurs within liberibacter species. 


\section{Conclusion}

The liberibacter species, whose genomes have been sequenced, universally contain three copies of essentially homogeneous 16S rRNA genes, and thus 16S-based phylogenies are sound. This copy number implies an evolutionary advantage of speed of population response over the metabolic cost associated with more copies. This suggests an ecosystem requiring speed to optimise growth in short periods rather than competing against other bacterial species, most likely to occur when conditions suitable for population growth are erratic. The lower evolutionary importance associated with metabolic cost of more rRNA gene copies implies that periods of low nutrient availability coincide with periods when cell division does not occur (low metabolic activity in bacteria). This suggests that the dormant phase of either insect or plant hosts is associated with low temperatures and therefore the disadvantage of high copy number is avoided.

\section{References}

1. Weisburg W, Barns S, Pelletier D, Lane D (1991) 16S ribosomal DNA amplification for phylogenetic study. J Bacteriol 173: 697-703.

2. Stevenson BS, Schmidt TM (1998) Growth ratedependent accumulation of RNA from plasmid-borne rRNA operons in Escherichia coli. J Bacteriol 180: 19701972.

3. Klappenbach JA, Dunbar JM, Schmidt TM (2000) rRNA operon copy number reflects ecological strategies of bacteria. Appl Environ Microbiol 66: 1328-1333.

4. Liao D (1999) Concerted evolution: molecular mechanism and biological implications. Am J Hum Genet 64: 24-30.

5. López-López A, Benlloch S, Bonfá M, Rodríguez-Valera F, Mira A (2007) Intragenomic 16S rDNA divergence in Haloarcula marismortui is an adaptation to different temperatures. J Mol Evol 65: 687-696.

6. Olivier A, Lee H, Côté J (2005) Study of the heterogeneity of $16 \mathrm{~S}$ rRNA genes in gammaproteobacteria: Implications for phylogenetic analysis. J Gen Appl Microbiol 51: 395-405.

7. Sun D, Jiang X, Wu QL, Zhou N (2013) Intragenomic heterogeneity of $16 \mathrm{~S}$ rRNA genes causes overestimation of prokaryotic diversity. Appl Environ Microbiol 79: 5962-5969.

8. Haapalainen M (2014) Biology and epidemics of Candidatus Liberibacter species, psyllid-transmitted plant-pathogenic bacteria. Ann App Biol 165: 172-198.

9. Jagoueix S, Bové J, Garnier M (1994) The phloemlimited bacterium of greening disease of citrus is a member of the $\alpha$-subdivision of the Proteobacteria. Int $\mathbf{J}$ Syst Bacteriol 44: 379-386.

10. Teixeira D, Eveillard S, Sirand-Pugnet P, Wulff A, Saillard C et al. (2008) The tufB-secE-nusG-rplKAJLrpoB gene cluster of the liberibacters: sequence comparisons, phylogeny and speciation. Int J Syst Evol Microbiol 58: 1414-1421.

11. Nelson WR, Munyaneza JE, McCue KF, Bové JM (2013) The Pangaean origin of "Candidatus Liberibacter" species. J Plant Path 95: 455-461.

12. Duan Y, Zhou L, Hall D, Li W, Doddapaneni H et al. (2009) Complete genome sequence of citrus huanglongbing bacterium, 'Candidatus Liberibacter asiaticus' obtained through metagenomics. Mol PlantMicr Int 22: 1011-1020.

13. Katoh H, Miyata S, Inoue H, Iwanami T (2014) Unique features of a Japanese 'Candidatus Liberibacter asiaticus' strain revealed by whole genome sequencing. PLoS ONE
9: e106109.

14. Lin H, Han CS, Liu B, Lou B, Bai X et al. (2013) Complete genome sequence of a Chinese strain of "Candidatus Liberibacter asiaticus". Genome Announc 1(2):e00184-13. doi:10.1128/genomeA.00184-13.

15. Zheng Z, Deng X, Chen J (2014) Whole-Genome Sequence of "Candidatus Liberibacter asiaticus" from Guangdong, China. Genome Announc 2(2):e00273-14. doi:10.1128/genomeA.00273-14.

16. Zheng Z, Deng X, Chen J (2014) Draft Genome Sequence of "Candidatus Liberibacter asiaticus" from California. Genome Announc 2(5):e00999-14. doi:10.1128/ genomeA.00999-14

17. Moreno-Enríquez A, Minero-García Y, Ramírez-Prado JH, Loeza-Kuk E, Uc-Varguez A et al. (2014) Comparative analysis of $16 \mathrm{~S}$ ribosomal RNA of 'Candidatus Liberibacter asiaticus' associated with Huanglongbing disease of Persian lime and Mexican lime reveals a major haplotype with worldwide distribution. Af J Microbiol Res 8: 2861-2873.

18. Nelson WR (2012) Reported single nucleotide polymorphisms on the 16S rRNA gene do not support haplotypes of "Candidatus Liberibacter asiaticus". Cit Res \& Tech 33: 75-79.

19. Bové JM (2014) Huanglongbing or yellow shoot, a disease of Gondwanan origin: Will it destroy citrus worldwide? Phytoparasitica : http://dx.doi.org/10.1007/ s12600-014-0415-4.

20. Islam M, Glynn J, Bai Y, Duan Y, Coletta-Filho H et al. (2012) Multilocus microsatellite analysis of 'Candidatus Liberibacter asiaticus' associated with citrus Huanglongbing worldwide. BMC Microbiol 12: 39.

21. Deng X, Zhou G, Li H, Chen J, Civerolo EL (2007) Nested-PCR detection and sequence confirmation of 'Candidatus Liberibacter asiaticus' from Murraya paniculata in Guangdong, China. Plant Dis 91: 10511051.

22. Damsteegt V, Postnikova E, Stone A, Kuhlmann M, Wilson C et al. (2010) Murraya paniculata and related species as potential hosts and inoculum reservoirs of "Candidatus Liberibacter asiaticus", causal agent of Huanglongbing. Plant Dis 94: 528-533.

23. Sandoval J, Sétamou M, da Graça J (2011) Host preference and suitability of native North American Rutaceae for the development of the Asian Citrus Psyllid, Diaphorina citri Kuwayama. 2nd International Research Conference on Huanglongbing : 197.

24. Teixeira D, Danet J, Eveillard S, Martins E, Junior W et al. (2005) Citrus huanglongbing in São Paulo State, Brazil: PCR detection of the 'Candidatus' Liberibacter species associated with the disease. Mol Cell Probes 19: 173-179.

25. Lopes SA, Frare GF, Camargo LEA, Wulff NA, Teixeira DC et al. (2010) Liberibacters associated with orange jasmine in Brazil: incidence in urban areas and relatedness to citrus liberibacters. Plant Path 59: 10441053.

26. Wulff NA, Zhang S, Setubal JC, Almeida NF, Martins EC et al. (2014) The complete genome sequence of Candidatus Liberibacter americanus, associated with citrus Huanglongbing. Mol Plant Microbe Interact 27: 163-176.

27. Liefting L, Weir B, Pennycook S, Clover G (2009) 'Candidatus Liberibacter solanacearum', a liberibacter associated with plants in the family Solanaceae. Int J Syst Evol Microbiol 59: 2274-2276.

28. Hansen AK, Trumble JT, Stouthamer R, Paine TD (2008) A new Huanglongbing species, "Candidatus Liberibacter psyllaurous", found to infect tomato and potato, is 
vectored by the psyllid Bactericera cockerelli (Sulc). Appl Env Microbiol 75: 5862-5865.

29. Munyaneza JE (2013) 'Candidatus Liberibacter solanacearum'. EPPO Bulletin 43: 197-201.

30. Tahzima R, Maes M, Achbani EH, Swisher KD, Munyaneza JE et al. (2014) First report of 'Candidatus Liberibacter solanacearum' on carrot in Africa. Plant Dis 98: 1426

31. Nelson WR, Fisher TW, Munyaneza JE (2011) Haplotypes of "Candidatus Liberibacter solanacearum" suggest long-standing separation. Euro J Pl Path 130: 512 .

32. Nelson WR, Sengoda VG, Alfaro-Fernandez AO, Font MI, Crosslin JM et al. (2013) A new haplotype of "Candidatus Liberibacter solanacearum" identified in the Mediterranean region. Euro J P1 Path 135: 633-639.

33. Teresani GR, Bertolini E, Alfaro-Fernandez A, Martínez C, Tanaka FAO et al. (2014) Association of 'Candidatus Liberibacter solanacearum' with a vegetative disorder of celery in Spain and development of a real-time PCR method for its detection. Phytopathology 104: 804-811.

34. Lin H, Lou B, Glynn JM, Doddapaneni H, Civerolo EL et al. (2011) The complete genome sequence of 'Candidatus Liberibacter solanacearum', the bacterium associated with potato Zebra Chip disease. PLoS ONE 6: e19135.

35. Fagen JR, Leonard MT, Coyle JF, McCullough CM, Davis-Richardson AG et al. (2014) Liberibacter crescens BT-1T gen. nov.; sp. nov., first cultured member of the Liberibacter genus. Int J Syst Evol Microbiol 64: 24612466.

36. Leonard M, Fagen J, Davis-Richardson A, Davis M, Triplett E (2012) Complete genome sequence of Liberibacter crescens BT-1. Stand Gen Sci 7: 271.

37. Wulff N, Eveillard S, Foissac X, Ayres A, Bové J (2009) rRNA operons and genome size of "Candidatus Liberibacter americanus", a bacterium associated with citrus huanglongbing in Brazil. Int J Syst Evol Microbiol 59: 1984-1991.

38. Larkin M, Blackshields G, Brown N, Chenna R, McGettigan P et al. (2007) Clustal W and Clustal X version 2.0. Bioinformatics 23: 2947-2948.

39. Matzura O, Wennborg A (1996) RNAdraw: an integrated program for RNA secondary structure calculation and analysis under 32-bit Microsoft Windows. Comput Appl Biosci 12: 247-249.

40. Lin H, Coletta-Filho HD, Han CS, Lou B, Civerolo EL et al. (2013) Draft genome sequence of "Candidatus Liberibacter americanus" bacterium associated with citrus Huanglongbing in Brazil. Gen Announc 1: e0027513; doi:10.1128/genomeA.00275-13 .

41. van Berkum P, Terefework Z, Paulin L, Suomalainen S, Lindström K et al. (2003) Discordant phylogenies within the rrn loci of Rhizobia. J Bacteriol 185: 2988-2998.

42. Lin H, Islam M, Bai Y, Wen A, Lan S et al. (2012) Genetic diversity of 'Candidatus Liberibacter solanacearum' strains in the United States and Mexico revealed by simple sequence repeat markers. Eur J Pl Path 132: 297-308

43. Wen A, Johnson C, Gudmestad NC (2013) Development of a PCR assay for the rapid detection and differentiation of "Candidatus Liberibacter solanacearum" haplotypes and their spatiotemporal distribution in the United States. Am J Potato Res 90: 229-236.

44. Case RJ, Boucher Y, Dahlihöf I, Holmström C, Doolittle $\mathrm{FW}$, et al (2007) Use of $16 \mathrm{~S}$ rRNA and rpoB genes as molecular markers for microbial ecology studies. Appl Environ Micro 73: 278-288

45. Coenye T, Vandamme P (2003) Intragenomic heterogeneity between multiple $16 \mathrm{~S}$ ribosomal RNA operons in sequenced bacterial genomes. FEMS
Microbiol Lett 228: 45-49.

46. Liu Q, Chen J, Munyaneza JE, Civerolo E, Wallis C (2013) Scanning electron microscopy and in vitro cultivation of endophytic bacteria from potato tubers afflicted with zebra chip disease. Can J Pl Path 35: 192199.

47. Sagaram US, Deangelis KM, Trivedi P, Andersen GL, Lu $S$ et al. (2009) Bacterial diversity analysis of Huanglongbing pathogen-infected Citrus using PhyloChips and 16S rDNA clone library sequencing. Appl Environ Micro 75: 1566-1574.

48. Fagen JR, Giongo A, Brown CT, Davis-Richardson AG, Gano KA et al. (2012) Characterization of the relative abundance of the Citrus pathogen $\mathrm{Ca}$. Liberibacter asiaticus in the microbiome of its insect vector, Diaphorina citri, using high throughput 16S rRNA sequencing. Open Microbiol J 6: 29-33.

49. Tyler H, Roesch L, Gowda S, Dawson W, Triplett E (2009) Confirmation of the sequence of 'Candidatus Liberibacter asiaticus' and assessment of microbial diversity in Huanglongbing-infected citrus phloem using a metagenomic approach. Mol Pl Mic Int 22: 1624-1634.

50. Hu H, Brlansky RH (2014) Live population dynamics of 'Candidatus Liberibacter asiaticus', the bacterial agent associated with citrus huanglongbing, in citrus and noncitrus plant hosts. Plant Dis 98: 876-884.

51. Johnson EG, Wu J, Bright DB, Graham JH (2014) Association of 'Candidatus Liberibacter asiaticus' root infection, but not phloem plugging with root loss on huanglongbing-affected trees prior to appearance of foliar symptoms. Pl Pathol 63: 290-298.

52. Pitman A, Drayton G, Kraberger S, Genet R, Scott I (2011) Tuber transmission of "Candidatus Liberibacter solanacearum" and its association with zebra chip on potato in New Zealand. Euro J P1 Path 129: 389-398.

53. Rashed A, Workneh F, Rush C (2014) Emergence of 'Candidatus Liberibacter solanacearum'-infected seed potato in relation to the time of infectio. Pl Dis 99:274280.

54. Dung T, Kyndt T, Duong T, Holsters M, Gheysen G (2009) Survival of Candidatus liberibacter asiaticus, causal agent of Huanglongbing disease, in remnants of 'Volkamer' lemon roots in Vietnam. J Plant Pathol 91: S4.97-112.

55. Hoffman MT, Doud MS, Williams L, Zhang M, Ding F et al. (2013) Heat treatment eliminates 'Ca.Liberibacter asiaticus' from infected citrus trees under controlled conditions. Phytopathol 103: 15-22.

56. Gasparoto M, Coletta-Filho H, Bassanezi R, Lopes S, Lourenço S et al. (2012) Influence of temperature on infection and establishment of 'Candidatus Liberibacter americanus' and 'Candidatus Liberibacter asiaticus' in citrus plants. Plant Pathol 61: 658-664

57. Manjunath K, Ramadugu C, Kund G, Trumble J, Lee R (2011) A tomato model system to study Citrus huanglongbing. Phytopathology 101: S113.

58. Hazeleger WC, Wouters JA, Rombouts FM, Abee T (1998) Physiological activity of Campylobacter jejuni far below the minimal growth temperature. Appl Environ Microbiol 64: 3917-3922.

59. Fotadar U, Zaveloff P, Terracio L (2005) Growth of Escherichia coli at elevated temperatures. J Basic Microbiol 45: 403-404.

60. Liefting L, Sutherland P, Ward L, Paice K, Weir B et al. (2009) A new 'Candidatus Liberibacter' species associated with diseases of solanaceous crops. Plant Dis 93: 208214. 